\title{
História do empreendedor do conhecimento contábil em Rondônia
}

\section{History of the accounting knowledge entrepreneur in Rondônia}

\author{
Bruna Lívia Timbó de Araújo ${ }^{1}$, José Moreira da Silva Neto², Jackson Balthazar de \\ Arruda Câmara ${ }^{3}$, Gleimiria Batista da Costa ${ }^{4}$
}

\begin{abstract}
RESUMO
Este artigo visa demonstrar a importância de um empreendedor do conhecimento no desenvolvimento da profissão contábil no Estado de Rondônia, ressaltando suas lutas, espirito de liderança e principais barreiras enfrentadas. Permeia pelo ponto crítico da busca incessante pela regulamentação da profissão e do espaço dentro dos campos profissionais e acadêmicos. O ponto crucial do artigo gira em torno da vontade do empreendedor do conhecimento de buscar a valorização e regularização da classe contábil no estado de Rondônia e ainda seu instinto de liderança que estiveram presentes em suas atitudes de labutação. A metodologia utilizada para desenvolver esta narrativa inicia com a identificação dos agentes, seguido pelo ponto crucial para demonstrar aos leitores a importância e a relevância da história narrada e ainda a causalidade que toda história tem acontecimentos intencionais ou não intencionais. Utilizaram-se recursos tecnológicos e técnicas de transcrições de fala para que as coletas das informações narradas fossem expressas com toda a emoção descrita pelo entrevistado. Observou-se que a liderança que acompanhou o profissional durante toda a luta foi essencial para alcançar todos os sucessos.
\end{abstract}

Palavras-chave: Empreendedorismo; Contabilidade; Liderança

;

\begin{abstract}
This article aims to demonstrate the importance of a knowledge entrepreneur in the development of the accounting profession in the State of Rondônia, emphasizing their struggles, leadership spirit and main barriers faced. It permeates through the critical point of the incessant search for the regulation of the profession and space within the professional and academic fields. The crucial point of the article revolves around the knowledge entrepreneur's will to seek the valorization and regularization of the accounting class in the state of Rondônia and also his leadership instinct that were present in his labor attitudes. The methodology used to develop this narrative starts with the identification of agents, followed by the crucial point to demonstrate to readers the importance and relevance of the narrated story and also the causality that every story has intentional or unintentional events. Technological resources and speech transcription techniques were used so that the collection of narrated information was expressed with all the emotion described by the respondent. It was observed that the leadership that accompanied the professional throughout the fight was essential to achieve all the successes.
\end{abstract}

Keywords: Keyword Entrepreneurship; Accounting; Leadership

${ }^{1}$ Universidade Federal de Rondônia. Email: brunaliviatimbo@gmail.com

${ }^{2}$ Universidade Federal de Rondônia. Email: msilva@unir.br

${ }^{3}$ Universidade Federal de Rondônia. Email :jacksoncamara@hotmail.com

${ }^{4}$ Universidade Federal de Rondônia. Email: gleimiria@unir.br 


\section{INTRODUÇÃO}

O contador - o profissional de contabilidade sempre contou histórias de dimensões quantitativas e qualitativas dos patrimônios objetos contábeis, por meio de ações de registros, mensurações, evidenciações - demonstrações alicerçadas em princípios contábeis restritivos e/ou norteadores. Todavia, na era do conhecimento precisamos enaltecer e reconhecer as contribuições dos desenvolvedores e empreendedores do conhecimento contábil.

Notáveis nas Ciências Contábeis como por exemplo: Sérgio de Iudícibus, Eliseu Martins, Eldon S,Hendriksen e tantos outros, tem grande parte de suas histórias, já contadas implicitamente nas suas obras sobre as teoria, práticas e disclosure informacional contábeis . Todavia, a história destes e outros notáveis como empreendedores do conhecimento deve ter dimensões muito além da história implícita nas literaturas contábeis que produziram.

Como os mundos do conhecimento também tem dimensões diversas, ou seja: global, continental, nacional, regional e local, a história do empreendedor do conhecimento deve focar o mundo de atuação do ator da história.

No projeto pedagógico do curso de ciências contábeis da Universidade federal de Rondônia na subárea de conhecimentos contábeis de "Estágios e/ou laboratório", existe uma disciplina voltada para o desenvolvimento da "liderança situacional nas ciências contábeis e controladoria". A finalidade desta disciplina no programa do curso é trabalhar e desenvolver a equidade das habilidades técnicas com as comportamentais em situações diversas no campo profissional da contabilidade.

A história que será contada neste artigo terá como dimensão de mundo de empreendedorismo do conhecimento contábil, o Estado de Rondônia/Brasil e se guiara pela metodologia sugerida por Kouzes e Posner, 2011, que recomendam os componentes para se contar uma história. Segundo esses autores (cientistas de liderança): devemos iniciar com a identificação dos agentes, ou seja, as pessoas que fizeram parte da história; seguir com o dilema ou o ponto crucial que deseja ser demonstrado aos leitores; enfatizar as intenções por meio da importância e relevância da história narrada; e a causalidade, pois toda história tem os acontecimentos intencionais e não intencionais que concretizaram aquela ação. 


\section{Situação crítica e central da história}

A história gira em torno da vontade do empreendedor do conhecimento de buscar a valorização e regularização da classe contábil no estado de Rondônia e ainda seu instinto de liderança que permeou suas atitudes de labutação.

\section{Objetivo geral}

O objetivo geral deste artigo é contar a história de um empreendedor na organização profissional e no desenvolvimento do conhecimento contábil no Estado de Rondônia.

\section{HISTÓRIA DO EMPREENDEDOR DO CONHECIMENTO CONTÁBIL EM RONDÔNIA/BRASIL}

Tendo como desafio um fato sobre o empreendedorismo na organização profissional e no desenvolvimento da aprendizagem contábil em uma região brasileira, carente de desenvolvimento sobre vários aspectos, recorreu-se a uma metodologia de liderança "conte uma história" para teorizar o processo de empreendedorismo na organização profissional e no desenvolvimento do ensino da contabilidade em Rondônia.

O ator protagonista da história é o contador, professor e auditor Antônio Rocha de Souza (Rochinha), com foco nos grandes avanços proporcionados por ele para a Contabilidade no Estado de Rondônia, desde a sua chegada até os dias atuais. Cabe aqui ressaltar que este homem de garra e amor pela Contabilidade teve papel crucial para a tamanha desenvoltura do Conselho Regional de Contabilidade no Estado, pois foi através desse amor que ele dedicou toda sua carreia a ajudar as pessoas e batalhou pela valorização e reconhecimento dessa classe junto aos órgãos federais.

\section{Origem e desenvolvimento do personagem central da história}

O Rochinha, nasceu em um pequeno lugarejo Maranhense chamada Barra da Onça, distrito da cidade de Santa Quitéria, onde residiu poucos anos. Sua infância com poucos recursos financeiros, porém regada de amor dos pais, deu-se na comarca de Curusu, atual município de São Benedito do Rio Preto. No auge dos seus treze anos de 
idade e com a criação do Banco da Borracha (no Maranhão), atualmente Banco da Amazônia, iniciava uma nova trajetória em sua vida.

O Banco da Borracha que foi criado com o propósito de financiar o trabalho dos seringalistas na Amazônia, entre eles o "Papai do Rochinha", que vislumbrou a oportunidade de ampliar sua atuação de agricultor para agricultor-seringueiro, nas margens do Rio Tapajós/Pará. Tal mudança esteve relacionada a uma jornada de dias e noites a bordo de um navio lote (na terceira classe) apreciando apenas a paisagem do céu e do mar (nada de terra).

Sua mãe, como boa esposa, sempre cuidou muito bem dos filhos, ajudava o marido na lavoura e sempre que podia fazia costuras para aumentar um pouco a renda familiar. Rochinha um filho dedicado sempre acompanhou os pais para onde tiveram que ir em busca de melhores condições, todavia nunca perdeu a oportunidade de estudar e buscar aprendizados, mesmo que tivesse que estudar sozinho, pois como ele mesmo se considera, eis autodidata. Em meio a tantas mudanças chegaram na cidade de Jacareacanga e foi lá que sua vida profissional se iniciou, atuou em uma cooperativa recebendo as comunicações por meio do código moce, sendo exclusivo nessa atuação, apenas ele recebia todas as mensagens.

Em meados de 1957 seu pai foi em busca da mina do Guaporé, após uma longa viagem de navio chegou ao Território Federal do Guaporé (atualmente Estado de Rondônia) no dia sete de setembro do mesmo ano, aportaram na terra prometida. Segundo Rochinha: "Uma região pacata que as pessoas não tinham dinheiro e quando tinham não havia nada para comprar, nem mesmo automóvel se via nas ruas, a carne bovina vinha da Bolívia, os peixes de Manaus", e assim foi o início de uma longa caminhada de sucesso nesse Eldorado, atual cidade de Porto Velho.

Nessa terra, Rochinha iniciou a vida profissional através do exército e por ter sobrado do contingente da cidade de Porto Velho, foi servir no município de Guajarámirim, na $6^{a}$ Companhia de Fronteira que tinha como missão guarda o Brasil e a fronteira, missão árdua pois haviam muitos índios na serra do Pacaás Novos e grande parte dos serviços eram tirados lá, com um medo danado, afirmou ele. Quando acabou de prestar os serviços militares voltou para a cidade de Porto Velho e então começou a estudar o ginásio comercial na Escola Técnica de Comércio, Estudo e Trabalho da Loja Maçônica de Estudo e Trabalho, dando seu primeiro passo na história da contabilidade. 
Sua primeira formação foi como auxiliar de escritório, em seguida fez o curso de guarda livro, sempre "aos troncos e barrancos", pois a escola dava aula de graça e os professores eram os próprios maçons. Suas inspirações sempre foram os autores mais conhecidos como Hilário Franco, Antônio Lopes de Sá e Elizeu Martins. Sempre estudou, mas não tinha em mente qual profissão iria seguir, aproveitava todas as oportunidade e cursos que tinham disponíveis na cidade ou até por correspondência.

O tempo foi passando ele foi trabalhando e só após três anos teve a oportunidade de fazer o curso de técnico em contabilidade, a partir deste dia iniciou sua carreira como professor. Seu sucesso foi tomando um grande lastro até que Rocha foi contratado pela secretaria do Estado para dar aula na Escola Normal do Guaporé, local onde também fez um curso de pedagogia. O espírito de liderança de Rochinha teve início com sua atuação como presidente do grêmio 13 de maio da Escola Normal.

Com a vinda do Projeto Rondon Rochinha teve a oportunidade de fazer o curso de licenciatura, porém não foi um curso de licenciatura plena. Todavia, quando podia ele fazia cursos paralelos e assim fez de Contabilidade de Custos, Auditoria, Análise Financeira e outros. Quando teve a oportunidade de concluir todos esses cursos, juntouse com um ex-aluno e abriu um escritório de contabilidade. Em seguida cursou bacharel em ciências contábeis pela Universidade Federal de Rondônia e ainda uma especialização em Contabilidade de Auditoria pela Universidade Federal de Uberlândia. Ele relatou que esse começo foi bastante árduo, pois o sistema de contabilidade utilizado era manual, tudo era feito a mão, os clientes mandavam todos os papeis que tinham na empresa e eles tinham que catalogar todos e em seguida fazer a escrituração manualmente, primeiro no borrador, para depois passar para o livro diário, razão, caixa e os demonstrativos para que a contabilidade saísse perfeita.

Tempos depois surgiram os primeiros sistemas contábeis que permitiam utilizar fichas para copiar e fazer a escrituração, exigindo o mesmo cuidado do manual ou até maior, pois as cópias eram feitas com tinta e água, caso rasgasse uma das folhas, estragava todo o trabalho feito. Após esse, surgiu uma maneira de copiar com gelatina que era mais simples e nós já levávamos todos os livros prontos, numerados, para a junta comercial apenas autenticar. A contabilidade mecanizada teve início com o primeiro computador do grupo ZORNITA, era uma dificuldade enorme para conseguir escriturar naquela máquina, Rocha afirma que teve que contratar um profissional 
específico para atuar nela, pois ele tinha em suas mãos a responsabilidade da contabilização de grandes empresas da região.

\section{A luta pela regularização da Contabilidade em Rondônia}

O primeiro grande obstáculo encontrado no estado em relação a regularização da profissão contábil estava no registro dos diplomas dos técnicos em contabilidade, seguido pelo pagamento da anuidade, quando já registrados, e do apoio de um conselho regional. Todos esses problemas eram transferidos a cidade de Manaus, vez que aqui não havia uma sede. Sabendo de todos esses contratempos o senhor Francisco Chagas Aragão, contabilista e bacharel em direito, foi a Manaus conversou com os membros do conselho e indicou o Rochinha para ser representante da primeira delegacia do Conselho de Contabilidade no Estado de Rondônia.

Assim, o empreendedor Rocha, instalou a primeira delegacia dentro de seu escritório, proporcionando uma maior facilidade para os profissionais, pois tinham acesso direto para dar entrada em todas as documentações que fossem necessárias aqui mesmo na cidade de Porto Velho. A delegacia perdurou por mais de dez anos e o número de profissionais só crescia cada dia mais, chegando a disputar com a cidade de Manaus. Paralelo a atividade de delegado na cidade de Porto Velho, Rocha era conselheiro e suplente do Conselho Regional de Contabilidade em Manaus.

Como forma de recompensar todo o trabalho feito por Rocha junto ao conselho, sem nenhuma remuneração ou mesmo ajuda de custo, o colegiado de Manaus resolveu indica-lo para ser Vogal da Junta Comercial, antigamente vinculada direto do Governo Federal. Todos esses trabalhos desenvolvidos por ele eram de forma gratuita e apenas para contribuir com o desenvolvimento da profissão. Quando participava de uma das edições do Congresso Brasileiro de Contabilidade na cidade de Cuiabá - MS ele deu entrado no primeiro requerimento solicitando ao presidente do CFC a realização de um estudo de viabilidade para desmembrar a delegacia de Rondônia do CRC - AM.

Paralela a sua atuação no conselho Rocha foi eleito presidente da junta comercial e teve mais uma iniciativa empreendedora de transformá-la em uma autarquia vinculada ao Governo do Estado e não mais ao Governo Federal, preparando toda a documentação e entregando ao Deputado Dr. Jacó para apreciação na Assembleia Legislativa e como já era de se esperar, obteve-se êxito, pois estava tudo completo e a documentação correta, era apenas uma questão de formalização. 
Rocha foi indagado durante a entrevista sobre seu sonho de deixar um legado, fazer um diferencial na classe contábil dentro do estado e respondeu com louvor que este sempre foi seu maior sonho vez que era uma classe desamparada, por esse motivo nunca deixou de ser professor, mesmo quando ocupou todos os cargos já mencionados. Afirmou ainda que para tomar essas iniciativas tinha que ser alguém que tivesse coragem e que fosse um líder, que tivesse esse espirito de liderança para fazer a diferença, saber guiar o grupo em todas as situações e ter pulso firme para alcançar as conquistas empreendedoras.

Quando falamos de liderança o entrevistado nos remeteu a um assunto bastante relevante e de muito impacto em todos os cargos os quais assumiu, o discurso. Afirmou que sempre se preparava previamente para todos os seus discursos, lia livros, preparava os textos que ia falar para não "fazer feio" diante do público e assim foi concretizando cada vez mais seu papel de líder, empreendedor e exemplo para os profissionais da classe e alunos que teve durante toda a caminhada.

As historias de sucesso não param por aqui, Rocha foi um dos grandes incentivadores e criadores do curso de Contabilidade da Universidade Federal de Rondônia no Campus de Cacoal, afirmou que juntamente com outros professores eles iam no domingo e voltam na sexta-feira à noite, todos os rendimentos financeiros eram deixados lá para a construção e estruturação do campus, até mesmo os alunos contribuíram. Mais tarde, nesse mesmo campus ele foi cursar seu Mestrado em Engenharia da Produção, uma parceria estabelecida entre a universidade de Santa Catarina e a UNIR.

Em meio a tantas coisas boas, no ano de 2006, esse grande líder e empreendedor descobriu um câncer no fígado e teve que fazer um transplante em dezembro do mesmo ano. Hoje curado dessa enfermidade conta que o único sonho que deixou de realizar foi fazer o doutorado, ele já tinha todos os planos para a tese, desejava continuar seus estudos sobre o sistema de custos, por ele desenvolvido em sua dissertação de mestrado, para as empresas que atuam no ramo de piscicultura no Estado de Rondônia.

No decorrer da entrevista Rochinha foi indago a respeito de qual área contábil ele estava situado para que pudéssemos entender melhor sua trajetória e seus passos como empreendedor. De forma surpreendente ele respondeu que na sua época o contador era "o cara que sabia tudo", ou seja, os donos de escritórios tinham que saber desempenhar todas as funções, responder a todos os questionamentos dos clientes, 
diferentemente de hoje que há especialistas para cada área e o profissional tem que escolher pelo menos uma delas para se aprofundar.

Além de empreendedor, líder e professor ele também é o único Auditor Independente do Estado de Rondônia (registrado na CMV) e devido a sua vasta experiência e trajetória de sucesso, foi indagado sobre qual empresa do Estado possui o melhor controle contábil. Afirmou que uma rede regional de supermercados possui um setor dotado de uma modernização inexplicável, tudo automatizado, todos os dados da empresa em arquivos digitais e que quando vai fazer suas auditorias são feitas em apenas em três dias e sem a necessidade de mexer em nenhum papel, apenas em contato com o responsável do setor de sistemas de informação, que, na sua concepção, é a peça mais importante de um setor contábil atualmente. Não podendo dizer qual a empresa que possui um melhor sistema, pois não conhece todas, mas garante que a que ele é o responsável é sensacional.

Levando em consideração toda a experiência vivida por ele, as diversas fases da evolução contábil presenciada ele afirma que para ser um bom profissional da contabilidade atualmente é necessário estudar sempre, fazer pesquisas, conhecer diversas áreas, mesmo que de forma generalizada, para quando necessário for saber onde buscar maiores informações. Para que a pessoa seja um bom contador gerencial é necessário entender a mecânica e a essência da contabilidade, quais os limites jurídicos, administrativos, deve haver uma dominância da língua estrangeira, pois a convergência para a contabilidade internacional exige esse conhecimento também.

Um dos entrevistadores ressaltou um ponto muito crucial ao questionar o que Rocha indicaria para compor o seu ativo no balanço de sua vida, se faltou algum reconhecimento, considerando essa tamanha trajetória. Ele ressalta que hoje o balanço não é mais real (com base em dados históricos) em decorrência dos testes de impairment podendo os valores serem revistos a qualquer tempo e afirmou que o reconhecimento maior que poderia haver era o da classe contábil no nosso Estado e assim aconteceu, então esse não foi um ativo que faltou ser lançado.

Constatando que o ativo estivesse completo pelo reconhecimento que a classe e a técnica contábil vêm tendo ao longo dos anos, não só no Estado, mas também pelos órgãos de controle, como a Receita Federal que teve que adequar-se a normas das IFRS. O entrevistado foi indagado sobre o passivo, sobre quais obrigações faltaram e se deixou a desejar em algum aspecto como profissional, filho, esposo ou pai. E como era 
de se esperar de um líder de sucesso, Rocha respondeu que não faltou nada, suas obrigações familiares sempre estiveram em primeiro lugar e nunca houve descuido algum com eles, pelo contrário sempre foram seu maior alicerce para alcançar os objetivos e metas traçados.

Quanto ao quesito profissional Rocha respondeu que no passivo são registradas sempre as obrigações que as empresas têm para que seja observada a capacidade financeira de honrar os compromissos, os empréstimos realizados e as dívidas existentes. É através desses registros que poderá haver a reciprocidade, o reconhecimento e a sensação de dever cumprido quando são "pagas" essas obrigações.

Entrando na seara da atuação profissional chegou-se a um impasse muito comum nas organizações, se a autonomia dos profissionais da contabilidade fosse efetiva haveria uma redução nos desfalques e roubos tão comuns? Rocha afirmou sem a menor dúvida que sim, ressaltando que a classe contábil deveria ter uma liberdade de atuação semelhante à dos auditores, pois existiria uma liberdade e independência para desempenhar as tarefas. Poderia haver um respeito maior a ética profissional, vez que ela é oriunda da filosofia e assim estaríamos trabalhando com o intelecto de cada profissional, com a responsabilidade social e pessoal de cada um, não deixando cair em tentações do destino, pois muitas das falcatruas acontecem em momentos que os profissionais estão mais necessitados ou com alguém da família doente e precisando de dinheiro para ajudar. Não há um respeito a ética e a filosofia de vida das pessoas esta cada vez mais banalizada.

Outro questionamento lhe foi feito quanto aos pontos cruciais de sua trajetória, ou seja, aqueles que foram determinantes para alcançar todo este sucesso empreendedor já expressado, ele respondeu que o primeiro foi a coragem. Coragem é uma palavra muito ampla, mas para Rocha está diretamente relacionada a enfrentar os obstáculos da vida, pois desde que nasceu suas batalhadas foram muitas e a coragem nunca lhe faltou. Dedicação foi outro ponto determinante, pois é necessário que as pessoas escolham um foco e um objetivo, o dele era a contabilidade, havia o sonho de transformar a contabilidade no Estado de Rondônia. Todas as demais conquistas foram frutos colhidos dessa dedicação, coragem, determinação e muita pesquisa.

Devido toda sua cautela e cuidado com a profissão, Rocha afirma que não houve nenhuma situação surpreendente, pois jamais assumiria uma responsabilidade que ele não achasse que fosse capaz de cumprir e que não tivesse conhecimento suficiente para 
liderar aquela equipe, como aconteceu com a Presidência da Junta Comercial, do Conselho Regional de Contabilidade e muitos outros cargos por ele ocupados. Ele ressalta que a presidência do CRC-RO foi de muito sucesso e muitas conquistas, pois já havia vivido muitas coisas, tinha uma bagagem profissional e pessoal muito grande, pode-se até afirmar que este foi um dos cargos de maior sucesso empreendedor. Contou que em uma reunião no Conselho Federal de Contabilidade ele precisava defender uma campanha de doação de órgãos e usou sua própria história para alcançar esse objetivo, fazendo com que todo o plenário se sensibilizasse ao afirmar que antes de fazer o transplante o CRC - RO inaugurou um plenário com o nome de Contador Antônio Rocha de Sousa, pois todo tinham certeza de que ele iria morrer, afirmou que este episódio foi inédito e muito marcante, vez que sua história de vida comoveu as pessoas de forma alegre, como ele mesmo leva a vida, e não com drama.

Diante destas afirmações podemos observar que humor sério, humor verdadeiro, contribuiu para muitas conquistas e sempre esteve presente na vida dele. Ele afirma ainda que esses acontecimentos de alegria fizeram com que muitas pessoas espalhadas pelo país o conhecessem e lembrassem-se dele com felicidade e como bons exemplos. Outra grande conquista que ele afirmou durante seu mandato como presidente foi a possibilidade de viajar pelo estado inteiro e conhecer as faculdades que foram criadas ao longo desses anos, participar de colações de grau, ter contato com os alunos e os futuros profissionais da classe contábil, aqueles que irão nos substituir no futuro. Ressaltou que nunca deixava a "peteca cair" em seus discursos, todos muito bem preparados e feitos exclusivos para cada momento, não perdendo sua tradição.

\section{O UAU DA HISTÓRIA}

- Rochinha um menino de origem da agricultura do interior do Maranhão;

- aos treze anos embarcou em um navio onde só se via céu e mar;

- foi profissional de "comunicação do código moce";

- estudante do ginásio comercial da escola Maçônica;

- número um em cursos de contabilidade até mesmo por correspondências;

- “empresário" de um escritório de contabilidade;

- sediou no seu escritório a primeira delegacia do Conselho de Contabilidade em Rondônia, vinculada a sede de Manaus;

- presidente da Junta Comercial do antigo Território Federal do Guaporé; 
- bacharel em Ciências Contábeis pela Universidade Federal de Rondônia;

- professor de Contabilidade na Universidade Federal de Rondônia;

- especialista em Contabilidade e Auditoria;

- mestre em Engenharia da Produção;

- presidente do Conselho Federal de Contabilidade de Estado de Rondônia;

- único auditor independente (CVM) do Estado de Rondônia;

- detentor de um novo fígado por meio de transplante;

- UAU! Um empreendedor!

\section{CONSIDERAÇÕES FINAIS}

A metodologia "Conte uma história" foi de grande valia para direcionar esta narração, pois permite o resgate de um déficit de valorização do profissional que durante sua carreira empreenderam em diversas áreas e que não estão sendo contabilizados seus reconhecimentos e lideranças. Tal metodologia poderá ser utilizada em outras áreas do conhecimento para trazer a luz da história as suas realizações e empreendedorismo.

\section{REFERÊNCIAS}

KOUZES, James M., POSNER, Barry Z. O Coração da Liderança: Os sete passos para estimular pessoas e aumentar resultados. São Paulo: Editora Gente, 2011.

HENDRIKSEN, Eldon S. e VAN BREDA, Michael F. Teoria da Contabilidade. São Paulo. Atlas, 1999.

IUDÍCIBUS, Sérgio de et al. Manual de Contabilidade Societária. São Paulo. Atlas, 2013.

IUDÍCIBUS, Sérgio de. Teoria da Contabilidade, 10ª ed. Atlas, 2010. 